\title{
RESEARCH
}

Open Access

\section{Circadian disruption of core body temperature in trauma patients: a single- center retrospective observational study}

\author{
Aurélien Culver ${ }^{1 \dagger}$, Benjamin Coiffard ${ }^{2,3 \dagger}$, François Antonini ${ }^{1}$, Gary Duclos $^{1}$, Emmanuelle Hammad $^{1}$, Coralie Vigne ${ }^{1}$,
} Jean-Louis Mege ${ }^{3}$, Karine Baumstarck ${ }^{4}$, Mohamed Boucekine ${ }^{4}$, Laurent Zieleskiewicz ${ }^{1}$ and Marc Leone ${ }^{1,3^{*}}$

\begin{abstract}
Background: Circadian clock alterations were poorly reported in trauma patients, although they have a critical role in human physiology. Core body temperature is a clinical variable regulated by the circadian clock. Our objective was to identify the circadian temperature disruption in trauma patients and to determine whether these disruptions were associated with the 28-day mortality rate.

Methods: A retrospective and observational single-center cohort study was conducted. All adult severe trauma patients admitted to the intensive care unit of Aix Marseille University, North Hospital, from November 2013 to February 2018, were evaluated. The variations of core body temperature for each patient were analyzed between days 2 and 3 after intensive care unit admission. Core body temperature variations were defined by three parameters: mesor, amplitude, and period. A logistic regression model was used to determine the variables influencing these three parameters. A survival analysis was performed assessing the association between core body temperature rhythm disruption and 28-day mortality rate. A post hoc subgroup analysis focused on the patients with head trauma.

Results: Among the 1584 screened patients, 248 were included in this study. The period differed from $24 \mathrm{~h}$ in 177 (71\%) patients. The mesor value $\left({ }^{\circ} \mathrm{C}\right)$ was associated with body mass index and ketamine use. Amplitude $\left({ }^{\circ} \mathrm{C}\right)$ was associated with ketamine use only. The 28-day mortality rate was $18 \%$. For all trauma patients, age, body mass index, intracranial hypertension, and amplitude were independent risk factors. The patients with a mesor value < $36.9^{\circ} \mathrm{C}(p<0.001)$ and an amplitude $>0.6^{\circ} \mathrm{C}(p<0.001)$ had a higher 28 -day mortality rate. Among the patients with head trauma, mesor and amplitude were identified as independent risk factors ( $\mathrm{HR}=0.40,95 \% \mathrm{Cl}[0.23-0.70]$, $p=0.001$ and $\mathrm{HR}=4.73,95 \% \mathrm{Cl}[1.38-16.22], p=0.01)$.

Conclusions: Our results highlight an association between core body temperature circadian alteration and 28-day mortality rate. This association was more pronounced in the head trauma patients than in the non-head trauma patients. Further studies are needed to show a causal link and consider possible interventions.
\end{abstract}

Keywords: Critical care, Multiple trauma, Mortality, Body temperature, Circadian rhythm, Mathematical computing

\footnotetext{
* Correspondence: marc.leone@ap-hm.fr

${ }^{\dagger}$ Aurélien Culver and Benjamin Coiffard are co-authors.

'Service d'Anesthésie et de Réanimation, APHM, Hôpital Nord, Aix Marseille

Université, Chemin des Bourrely, 13915 Marseille, France

${ }^{3} \mathrm{CNRS}$, IRD, MEPHI, IHU Méditerranée Infection, Aix Marseille Université,

Marseille, France

Full list of author information is available at the end of the article
}

(c) The Author(s). 2020 Open Access This article is distributed under the terms of the Creative Commons Attribution 4.0 International License (http://creativecommons.org/licenses/by/4.0/), which permits unrestricted use, distribution, and reproduction in any medium, provided you give appropriate credit to the original author(s) and the source, provide a link to the Creative Commons license, and indicate if changes were made. The Creative Commons Public Domain Dedication waiver (http://creativecommons.org/publicdomain/zero/1.0/) applies to the data made available in this article, unless otherwise stated. 


\section{Background}

Major trauma is the leading cause of mortality among patients admitted in the intensive care unit (ICU) [1]. Two components affect the outcome of trauma patients: organ damage due to direct trauma and post-traumatic systemic inflammation progressing to multiorgan failure [2]. These pathologic events are responsible for disrupting the physiological mechanisms.

The circadian clock is a biological function that has been particularly preserved throughout species evolution, and it is present in almost all living organisms [3]. In humans, circadian clock is regulated by a central stimulator located in the suprachiasmatic nuclei of the hypothalamus $[4,5]$. It synchronizes intracellular processes and vital functions, including core body temperature (CBT), sleep, cardiovascular and respiratory functions, coagulation, and immunity to the external environment $[6,7]$. This system is directed by a set of specific genes known as the "clock genes," of which about 10 are identified $[8,9]$.

CBT is a stable physiological variable, whose variations are correlated to the activity of the circadian clock [10, 11]. In healthy subjects, the normal values oscillate by about $0.5^{\circ} \mathrm{C}$ per day and are around an average of $37.0^{\circ} \mathrm{C}$ [12]. CBT reaches its lowest value between 4:00 am and 6:00 am and rises gradually during the day to a maximal value between 4:00 pm and 6:00 pm [13]. In routine, clinicians interpret its value dichotomously, reporting the presence or absence of fever. However, several studies have reported the importance of considering temperature variations rather than a single isolated value $[14,15]$.

The circadian clock cannot be directly evaluated in humans. Three variables have been used to indirectly assess the circadian clock: CBT and the levels of cortisol and melatonin $[16,17]$. Studies have assessed the circadian clock of trauma patients admitted to the ICU [1618]. Circadian clock disruption seems to be frequent in this population [16-21]. In a previous study, we showed that trauma patients exhibited early impaired circadian rhythms of biological mediators [22]. Importantly, this early disruption was associated with an increased risk of sepsis development during the ICU stay.

Here, we hypothesized that the assessment of CBT variations is relevant, particularly at the early phase of ICU admission, to identify the patients at high risk of mortality. Our study aims at identifying an association between circadian clock disruption based on CBT analysis and 28-day mortality rate in trauma patients.

\section{Materials and methods}

\section{Study design}

A single-center retrospective observational study was conducted in the Trauma Center of Aix Marseille
University, Marseille, France. This center includes a 15bed ICU and a shock room dedicated to the early management of trauma patients. As per the French law [23], the research protocol has been approved by the Ethics Committee of the French Society of Anesthesia and Intensive Care Medicine (IRB CERAR-00010254) and by the local Computer and Freedom Committee (CIL 201835). As the study was retrospective, the written consent was waived by our Ethics Committee.

\section{Patients}

All patients registered in our department's database and admitted to ICU for major trauma between November 2013 and February 2018 and monitored for at least $72 \mathrm{~h}$ of continuous CBT measurements were included. Major trauma was defined as a patient with at least one lifethreatening lesion or whose trauma severity suggests the existence of such a lesion. Vittel algorithm was used to define a trauma patient [24]. Exclusion criteria were as follows: (1) death within the first $72 \mathrm{~h}$; (2) ICU stay $<72$ $\mathrm{h}$; (3) absence of CBT monitoring during the first $72 \mathrm{~h}$ after ICU admission; (4) incomplete data on CBT monitoring with a lack of data exceeding a total of $6 \mathrm{~h}$ between $24 \mathrm{~h}$ and $72 \mathrm{~h}$ after ICU admission; and (5) use of a targeted temperature control system and renal replacement therapy. Because targeted temperature control was used for patients with cardiac arrest, they were excluded from the study.

\section{Demographic data}

Demographic and clinical data were retrospectively extracted from the electronic medical files. At admission, we recorded age, gender, body mass index (BMI), Glasgow Coma Scale score, Simplified Acute Physiology Score (SAPS2), Acute Injury Score (AIS), and Injury Severity Score (ISS).

During the first $72 \mathrm{~h}$, we collected data on the intracranial hypertension (defined as an episode of intracranial pressure $>20 \mathrm{mmHg}$ for more than $5 \mathrm{~min}$ ), mechanical ventilation, need for urgent surgery or craniectomy, administration of acetaminophen, use of sedative agents (benzodiazepine, ketamine, sufentanil, propofol), use of neuromuscular blocker agents, intrahospital transport, and blood transfusion. The durations of mechanical ventilation, catecholamine infusion (if any), ICU, and hospital stay and the 28-day mortality rate were also recorded.

\section{Core body temperature curves}

For each patient, the first $72 \mathrm{~h}$ of CBT measurements were extracted from our ICU database. Since the trauma patients were often disconnected from the monitors for radiological or surgical procedures during the first $24 \mathrm{~h}$, we selected the timeslot between 
$24 \mathrm{~h}$ and $72 \mathrm{~h}$ after ICU admission. CBT was measured using a Foley urinary catheter (400 TM temperature sensor, Covidien ${ }^{\mathrm{Tx}}$, Boulder, USA) directly connected to the patient's monitor (Intellivue 70, Philips, Eindhoven, Netherlands). CBT data were recorded at the rate of 1 value per minute (representing 2880 points for the study period).

\section{Patient management}

The management of trauma patients was based on European guidelines [25]. The trauma patients were bedridden for the first few ICU days, and they were fed by the enteral route continuously if possible. According to our protocol based on international guidelines [25], sedation was used to target a Richmond Agitation-Sedation Scale (RASS) at 0 in the absence of intracranial hypertension or acute respiratory distress syndrome (RASS at -5 ). The ambient ICU temperature was automatically set between $22^{\circ} \mathrm{C}$ and $24^{\circ} \mathrm{C}$ through a thermostat. Light was set as daylight during the day and dark for night. Acetaminophen was administered in the patients with brain injury and body temperature exceeding $37.5^{\circ} \mathrm{C}$ and those with pain above 30 in the visual analog scale or above 6 in the behavioral pain scale. Only six patients received additive use of non-steroidal anti-inflammatory drugs. Nursing care was provided continuously [26]. Intensivists were in a house for $24 \mathrm{~h} / 7$ days with rounds at $11 \mathrm{am}, 6 \mathrm{pm}$, and $11 \mathrm{pm}$. Our ICU follows the organization of French ICUs [26].

\section{Fourier transformation and Cosinor analysis}

We assessed the CBT for each patient. To determine the most probable time of temporal oscillation (first harmonic), a spectral resolution method (Fourier transformation) was used [27]. Using the least squares method, unique Cosinor analysis then adjusted the sinusoidal wave to the time series (Additional file 1). This model uses the following formula: $y=$ mes $+\mathrm{amp} \times \cos (2(t-$ $\phi) / p)$, where " $p$ " is the period found by the Fourier transformation, " $y$ " is the marker value $(\mathrm{CBT})$, " $t$ " represents the time of day in decimal mode, "mes," "amp," and " $\phi$ " represent respectively the mesor, the amplitude, and the acrophase of the rhythm (see Additional file 2 and Additional file 3 for the definition of these variables). Additional file 4 illustrates four examples of CBT rhythm modeling.

\section{Statistical analysis}

Statistical analyses were performed with the public software $\mathrm{R}$ version 3.5.1 R Development Core Team (2005) (R: A language and environment for statistical computing. R Foundation for Statistical Computing, Vienna, Austria. ISBN 3-900051-07-0, URL http://
www.R-project.org). The initial population characteristics were expressed in number (percentages) for categorical variables, and as the mean \pm standard deviation (SD) or median and interquartile [IQR] for continuous data according to the distribution (Shapiro-Wilk test). Associations between clinical variables and circadian parameters (period, mesor, and amplitude) were studied by logistic regression with the general linear model. Regression coefficients $\beta \pm$ standard error (SE) and odds ratios (OR) obtained in this way were used to assess the relative predictive effects of the independent variables. A survival analysis was performed using Cox's proportional risk model to determine the factors associated with 28-day mortality. Relative risks, hazard ratio (HR), and their 95\% confidence intervals $(95 \% \mathrm{CI})$ were calculated. All variables with $p<0.05$ values in univariate models were included in the final multivariate models. The 28-day survival between groups was calculated by the logrank test, and survival curves were obtained by the Kaplan-Meier method. To form groups with the highest survival difference, the best significant threshold of the circadian parameter for predicting 28-day mortality was calculated with the cutp function of $\mathrm{R}$ to determine the optimal cut point for a continuous variable in the Cox model. A post hoc subgroup analysis was performed in the patients with head trauma defined by the notification of this term in the initial medical file. For all tests, statistical significance was defined by $p$ values less than 0.05 .

\section{Results}

\section{Patients}

A total of 1584 patients were screened during the 4-year study period. Among them, 248 (15.7\%) fulfilled the inclusion criteria (Fig. 1). The clinical features and initial treatments are reported in Table 1. Most patients were young males. Mechanical ventilation and urgent surgery were required in $74 \%$ and $57 \%$ of the patients, respectively. The 28 -day mortality rate was $18 \%$.

\section{Core body temperature rhythm}

Periodic regressions were extracted from individual data (Additional file 5). Figure 2 shows the distribution of the three circadian parameters (i.e., period, mesor, and amplitude). The median [IQR] values of the mesor, amplitude, and period were $37.5^{\circ} \mathrm{C}[37.1-37.9], 0.35^{\circ} \mathrm{C}$ [0.26-0.54], and $24 \mathrm{~h}$ [23-48], respectively. Only 71 (29\%) patients had a period between $22 \mathrm{~h}$ and $26 \mathrm{~h}$, while $75(30 \%)$ patients exhibited a period longer than or equal to $48 \mathrm{~h}$. In contrast, the mesor and amplitude were in the normal ranges. 


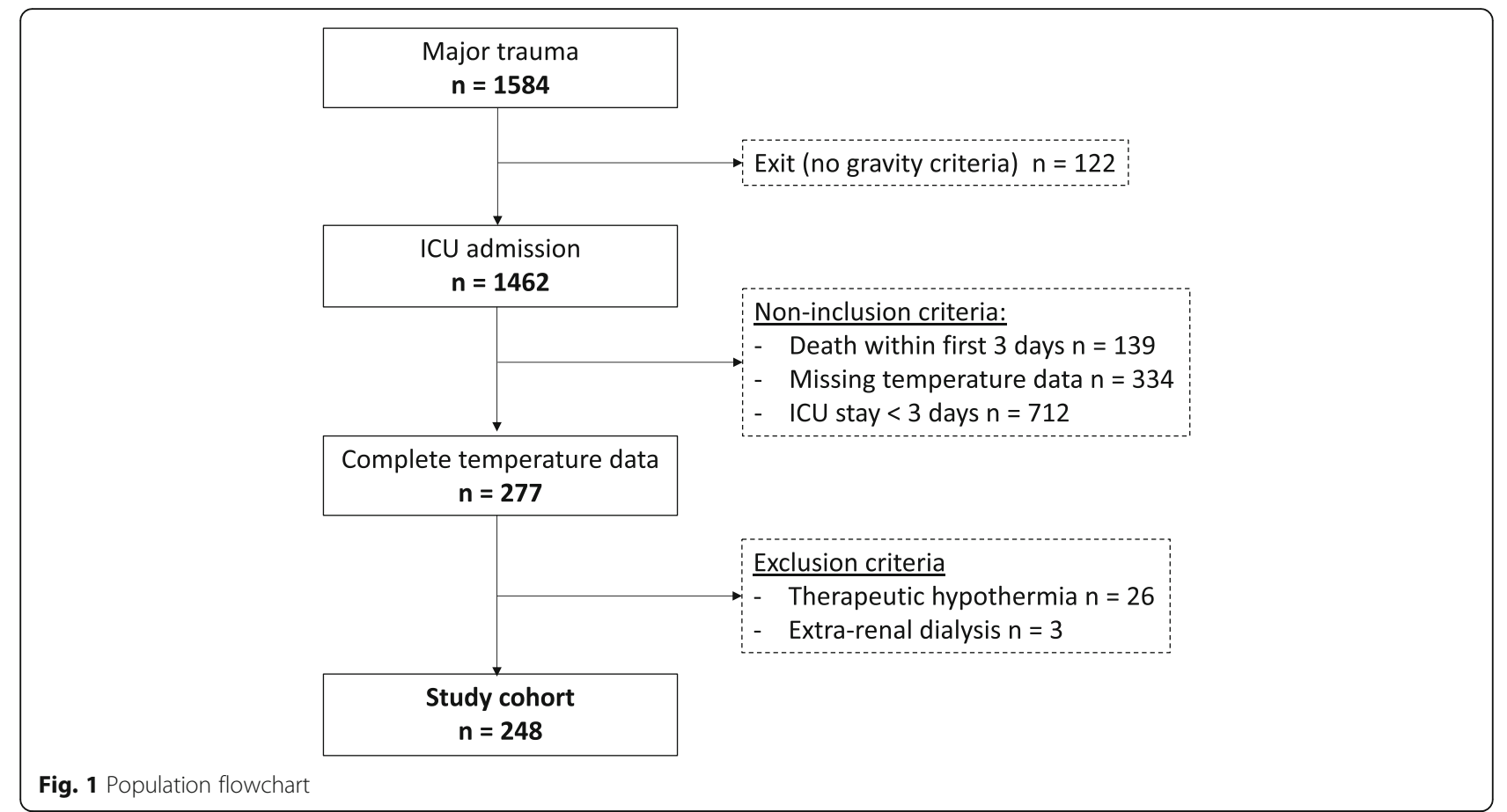

\section{Patient characteristics associated with core body temperature rhythm}

The results of the univariate logistic regression analysis are reported in Additional file 6. In the multivariate analysis, the mesor of the CBT significantly increased with increasing BMI while it decreased with ketamine infusion (Additional file 7). The amplitude significantly increased with ketamine infusion.

\section{Core body temperature rhythm and 28-day mortality}

The results of the univariate and multivariate Cox proportional survival analyses are reported in Table 2. In the multivariate analysis, age, intracranial hypertension, and amplitude of the CBT were identified as independent risk factors for 28-day mortality rate. The mesor (as a continuous variable) was almost significantly associated with 28-day mortality rate $(\mathrm{HR}=0.62,95 \% \mathrm{CI}$ [0.37-1.03], $p=0.064)$. BMI was a protective factor of 28-day mortality.

Figure 3 shows the Cox regression model fitting the continuous association between mesor or amplitude and the $\log$ relative hazard of 28 -day mortality. The risk of 28-day mortality was increased for the lowest mesor (< $\left.37.5^{\circ} \mathrm{C}\right)$ and highest amplitude $\left(>0.5^{\circ} \mathrm{C}\right)$ values. A protective effect was identified in patients with CBT amplitude close to the physiological values (between 0.2 and $\left.0.5^{\circ} \mathrm{C}\right)$.

The best significant thresholds of the circadian parameters for predicting 28-day mortality were $36.9^{\circ} \mathrm{C}$ for the mesor $(p<0.001)$ and $0.6^{\circ} \mathrm{C}$ for the amplitude $(p<$ 0.001) (see Kaplan-Meier curves on Fig. 4).

\section{Head trauma patients}

The 176 head trauma patients were compared with the non-head trauma patients (Table 3). The ISS and the exposure to mechanical ventilation were higher in the head trauma patients, as compared with the nonhead trauma patients. The results of the univariate and multivariate analyses in the head trauma and the non-head trauma patients are reported in Table 4. Mesor and amplitude were identified as independent risk factors in the head trauma patients $(\mathrm{HR}=0.40$, 95\% CI [0.23-0.70], $p=0.001$ and $\mathrm{HR}=4.73,95 \% \mathrm{CI}$ [1.38-16.22], $p=0.01)$. None of the three variables were independently associated with 28-day mortality in the non-head trauma patients. Figure 5 illustrates the Cox regression model fitting the continuous association between mesor or amplitude and the log relative hazard of 28-day mortality for head trauma patients and non-head trauma patients.

\section{Discussion}

Our study aimed at highlighting the circadian clock disruption in trauma patients. We showed that CBT profiles were disrupted early, with alterations in mesor, period, and amplitude. In addition, the changes in CBT variations were associated with the 28 -day mortality rate. 
Table 1 Patient characteristics and outcome

\begin{tabular}{|c|c|}
\hline Variables & Cohort $(n=248)$ \\
\hline Age, years & 36 [23-53] \\
\hline Sex, men & $181(73.0)$ \\
\hline $\mathrm{BMl}, \mathrm{kg} / \mathrm{m}^{2}$ & $24[22-26]$ \\
\hline \multicolumn{2}{|l|}{ Initial trauma condition } \\
\hline Glasgow Coma Scale & $8[5-14]$ \\
\hline Head injury & $176(71.0)$ \\
\hline Intracranial hypertension & $80(32.3)$ \\
\hline Surgery in the first $24 \mathrm{~h}$ & $142(57.3)$ \\
\hline SAPS2 & $47 \pm 16$ \\
\hline \multicolumn{2}{|l|}{ Severity of trauma } \\
\hline ISS & $34[25-43]$ \\
\hline AlS head or neck & $4.5[0-5]$ \\
\hline AlS chest & $3[0-3]$ \\
\hline AlS abdomen or pelvic & $0[0-2]$ \\
\hline AIS extremities & $0[0-2]$ \\
\hline AIS rachis & $0[0-2]$ \\
\hline \multicolumn{2}{|l|}{ Treatments } \\
\hline Mechanical ventilation & $184(74.2)$ \\
\hline Acetaminophen & $159(64.1)$ \\
\hline Benzodiazepine & $136(54.8)$ \\
\hline Opioids & $202(81.4)$ \\
\hline Neuro-muscular blockers & $37(14.9)$ \\
\hline Ketamine & $24(9.7)$ \\
\hline Craniectomy & $13(5.2)$ \\
\hline Transfusion & $0[0-3]$ \\
\hline In-hospital transport & $135(54.4)$ \\
\hline \multicolumn{2}{|l|}{ Outcome } \\
\hline 28-day mortality & $45(18.1)$ \\
\hline Days on mechanical ventilation & $6[3-13]$ \\
\hline Days on vasopressor infusion & $2[1-4]$ \\
\hline Day in the ICU stay & $9[5-18]$ \\
\hline Days in the hospital & 12 [7-23] \\
\hline
\end{tabular}

Results are expressed as median [IQR] for quantitative variables and number (\%) for categorical variables

BMI body mass index, SAPS2 Severity Assessment Physiology Score 2, ISS Injury Severity Score, AIS Abbreviated Injury Scale

This finding suggests that the circadian clock may play a major role in the host response to traumatic insults.

Our findings are in line with those of previous studies $[28,29]$. In a cohort of 61 ICU patients, Drewry et al. predicted the patients who would develop sepsis up to $72 \mathrm{~h}$ before the diagnosis by comparing the temperature profiles of the patients with those of controls [28]. In 22 critically ill patients, Papaioannou et al. used temperature variability to differentiate those with fever due to infection and those with fever due to a non-
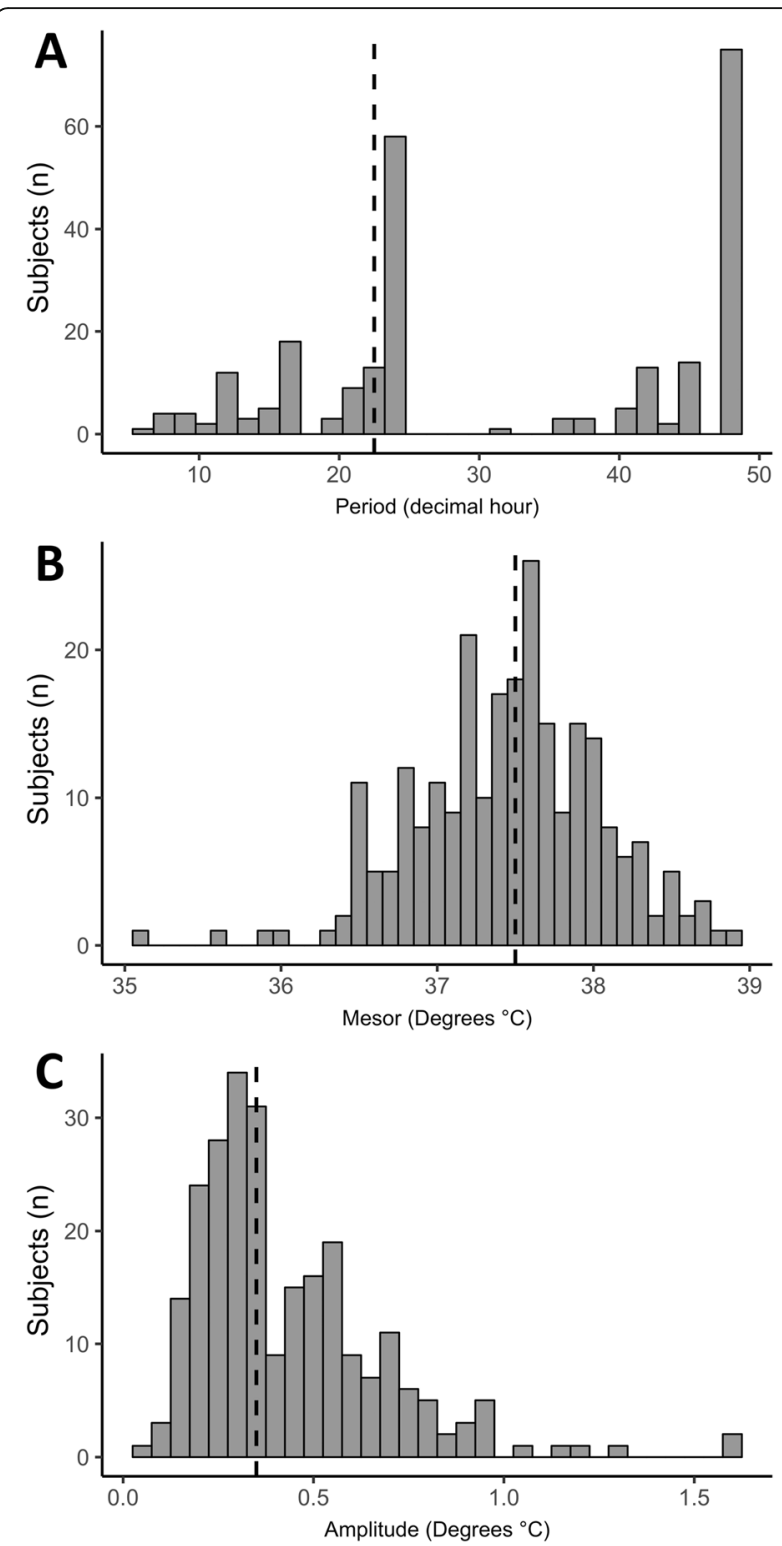

Fig. 2 Distribution of the three rhythm parameters of the temperature. a Period. b Mesor. c Amplitude. The median [IQR] values (discontinuous bar) of the period, mesor, and amplitude were $24 \mathrm{~h}[23-48], 37.5^{\circ} \mathrm{C}$ [37.1-37.9], $0.35^{\circ} \mathrm{C}$ [0.26-0.54], respectively

infectious cause [29]. These data underline the importance of considering temperature variations instead of an isolated single value.

In our study, several variables were associated with CBT variations. BMI was shown to influence CBT during both the perioperative period and ICU stay [30, 31]. Interestingly, higher CBT values were reported in overweight patients. Of note, the overweight ICU patients had a better outcome than those with normal BMI [32]. Low temperature values were previously reported in patients with traumatic brain injury [33, 34]. We previously 
Table 2 Survival analysis assessing 28-day mortality, patient characteristics, and circadian rhythm parameters of the temperature

\begin{tabular}{|c|c|c|c|c|}
\hline & \multicolumn{2}{|l|}{ Univariate } & \multicolumn{2}{|l|}{ Multivariate } \\
\hline & $\mathrm{HR}[95 \% \mathrm{Cl}]$ & $p$ & $\mathrm{HR}[95 \% \mathrm{Cl}]$ & $p$ \\
\hline \multicolumn{5}{|l|}{ Clinical variables } \\
\hline Age & $1.04[1.03-1.06]$ & $<0.001$ & $1.06[1.04-1.08]$ & $<0.001$ \\
\hline Sex (male) & $1.73[0.81-3.72]$ & 0.16 & & \\
\hline Body mass index & $0.91[0.83-0.99]$ & 0.04 & $0.83(0.75-0.93)$ & $<0.001$ \\
\hline Glasgow Coma Scale & $0.90[0.84-0.97]$ & 0.005 & & \\
\hline Traumatic brain injury & $2.05[0.95-4.39]$ & 0.07 & & \\
\hline Intracranial hypertension ${ }^{a}$ & $5.70[3.03-10.73]$ & $<0.001$ & $5.60[2.91-10.76]$ & $<0.001$ \\
\hline Surgery at admission & $0.74[0.41-1.33]$ & 0.32 & & \\
\hline ISS & $1.01[0.99-1.03]$ & 0.26 & & \\
\hline \multicolumn{5}{|l|}{ Temperature rhythm } \\
\hline Period & $1.00[0.98-1.02]$ & 0.65 & & \\
\hline Mesor & $0.42[0.27-0.66]$ & $<0.001$ & $0.62[0.37-1.03]$ & 0.064 \\
\hline Amplitude & $4.25[1.58-11.41]$ & 0.004 & $3.28[1.15-9.30]$ & 0.026 \\
\hline
\end{tabular}

found a decreased expression of Per 3 in this population [22]. In addition, in our ICU, ketamine was used as a sedative agent in the patients with intracranial hypertension [35]. In rats, ketamine induced dose-dependent hypothermia because of its anti-NMDA effect [36]. This mechanism may explain the association between the decreased CBT amplitude and the administration of ketamine.

The analysis of the period provided surprising results. Indeed, most trauma patients had a period different from the 24-h rhythm. In a cohort of 28 patients without traumatic brain injury, Gazendam et al. showed delayed acrophasis in the most severely ill patients, suggesting a profound alteration of the period associated with critical illness [21]. This is in line with our biological findings showing that acrophase was delayed for most critical mediators. This delay was associated with an increased rate of infection during the ICU stay [22].

Our methodology relied on two mathematical models. First, we performed a Fourier transformation or spectral analysis. For each patient, the spectral analysis identifies the most likely temperature curve period. Then, a Cosinor analysis, based on a sinusoidal approximation of a periodic value, allowed the calculation of three variables, namely, mesor, amplitude, and period. In contrast, Drewry et al. [28] requested visual advice from a group of physicians to identify CBT clock disturbances. Gazendam et al. [21] used a Cosinor function, but the time
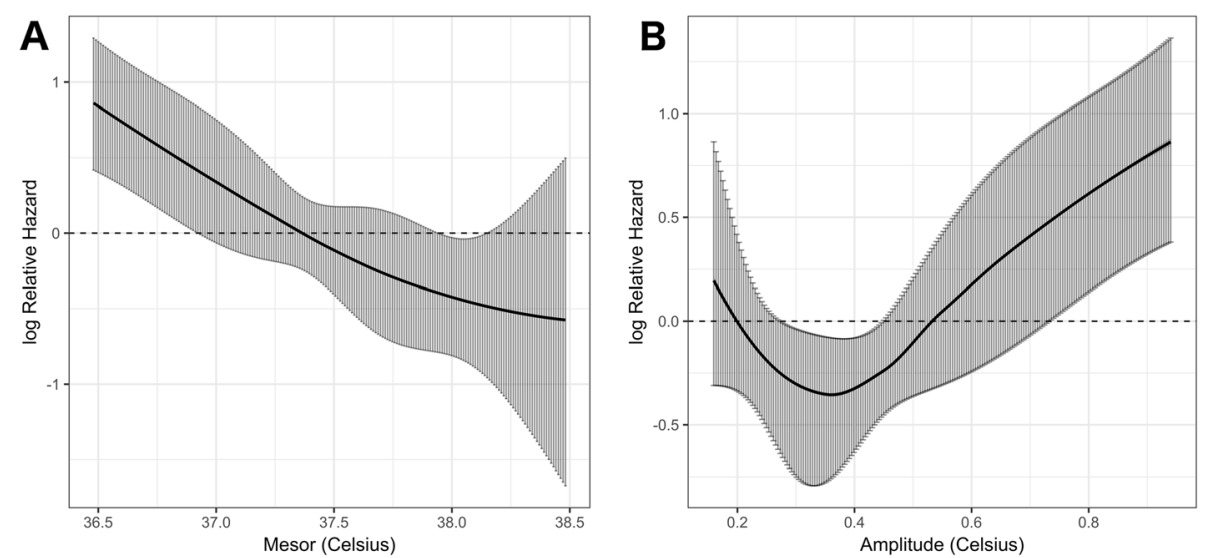

Fig. 3 Cox regression model fitting the association between temperature and the log relative hazard of 28-day mortality. a Mesor. b Amplitude. Black curve represents the estimates of the model and gray bars represent the $95 \%$ confidence interval bands 


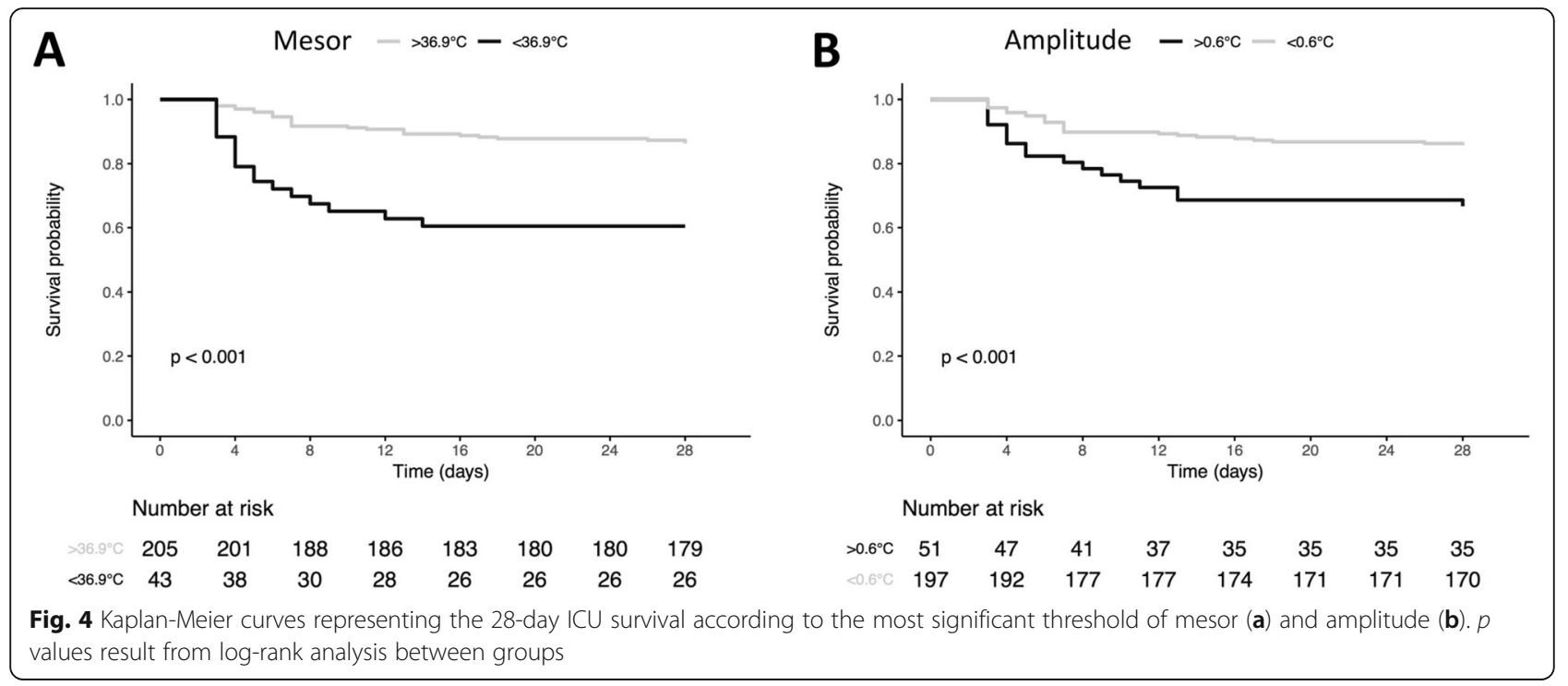

period was set at $24 \mathrm{~h}$ for all patients. Papaioannou et al. [37] analyzed approximate entropy of CBT within $24 \mathrm{~h}$ after nosocomial infection diagnosis to predict the mortality rate. The use of different methods complicates the comparisons of the findings of those studies. We made an attempt to approximate the most likely temperature cycle period. However, the Fourier transformation showed that 75 patients had a rhythm period longer than or equal to $48 \mathrm{~h}$. This may reflect a total abolition of circadian rhythm or a longer period that would require several days of analysis.

In our study, advanced age, intracranial hypertension, and early increase in CBT amplitude were independent risk factors for 28-day mortality. Thresholds for mesor $\left(<36.9^{\circ} \mathrm{C}\right)$ (i.e., the average value of CBT) and amplitude $\left(>0.6{ }^{\circ} \mathrm{C}\right)$ were associated with poor outcomes. Hypothermia is an independent risk factor for increased 28 -day mortality $[38,39]$. Amplitude was assessed in small cohorts of patients. In 15 patients, Tweedie et al. [19] showed that the CBT amplitude was $>0.15^{\circ} \mathrm{C}$ in non-survivors. In 86 patients with traumatic brain injury, Kirkness et al. reported significantly higher temperature amplitude of $0.1^{\circ} \mathrm{C}$ among non-survivors [40]. Conversely, other studies found that a decreased amplitude during the ICU stay was associated with the severity of illness and the mortality rate [41, 42]. However, these data do not contradict our results. Indeed, the logarithmic analysis of the mortality risk as a function of amplitude showed a trend toward excess mortality in the patients with reduced amplitude. In fact, it seems that the 28-day mortality rate was associated with deviation from the normal values of CBT [41-43]. Of note, our findings clearly show significant differences between the head trauma patients and the non-head trauma patients.
The effects of CBT disturbances are more pronounced in the head trauma patients.

Our study has several strengths. Our protocol included a large number of patients, as compared to previous studies [21, 28, 37, 42, 43]. Temperature measurements were collected from a central site-this point being the most common limitation encountered in other studies $[21,28,37,40,44]$. Bladder temperature monitoring is a validated method for determining $\mathrm{CBT}$-with a minimal error margin and a good correlation with CBT [45]. In addition, this monitoring is simple and inexpensive. Finally, our automatic system of recording at the rate of 1 value per minute resulted in a large amount of data, making our analysis reliable.

This study has some limitations. First, we cannot provide a cause-effect relationship between the different events. Second, owing to our methodology, we were unable to evaluate the effects of the external components such as ambient temperature, physical activity, and feeding [46]. However, in our ICU, as reported above, the room temperature was set by a thermostat. Physical activity and postural changes affect CBT [46], but in the ICU patients, these effects are limited, because $74 \%$ of them were on mechanical ventilation. Our patients were bedridden during the study period. Most of the included patients received continuous enteral feeding, erasing the effects of meals between day and night [47]. The light exposure was not recorded, but a local protocol ensured the quality of patients' sleep with daylight during the day and darkness at night. Third, accidental disconnections of the CBT recording system occurred during the study period. The consequences were limited by the noninclusion of patients with a lack of data exceeding $6 \mathrm{~h}$. Fourth, few treatments such as fluid expansion were not 
Table 3 Patient characteristics and outcome according to head trauma

\begin{tabular}{|c|c|c|c|}
\hline Variables & Head trauma $(n=176)$ & Non-head trauma $(n=72)$ & $p$ \\
\hline Age, years & $36[23-54]$ & 35 [24-49] & 0.86 \\
\hline Sex, men & $127(72.0)$ & $54(75.0)$ & 0.65 \\
\hline $\mathrm{BMl}, \mathrm{kg} / \mathrm{m}^{2}$ & $24[22-26]$ & $24[23-26]$ & 0.36 \\
\hline \multicolumn{4}{|l|}{ Initial trauma condition } \\
\hline Glasgow Coma Scale & $6[4-10]$ & 15 [14-15] & $<0.001$ \\
\hline \multicolumn{4}{|l|}{ Head injury } \\
\hline Intracranial hypertension & $80(45.5)$ & $0(0.0)$ & - \\
\hline Surgery in the first $24 \mathrm{~h}$ & $84(47.7)$ & $58(80.6)$ & $<0.001$ \\
\hline SAPS2 & $48 \pm 16$ & $42 \pm 17$ & $<0.001$ \\
\hline \multicolumn{4}{|l|}{ Severity of the trauma } \\
\hline ISS & $34[25-43]$ & $27[23-41]$ & 0.02 \\
\hline AlS head or neck & $5[4-5]$ & $0[0-0]$ & - \\
\hline AlS chest & $2[0-3]$ & $3[0-3]$ & 0.02 \\
\hline AlS abdomen or pelvic & $0[0-0]$ & $2[0-4]$ & $<0.001$ \\
\hline AIS extremities & $0[0-2]$ & $0[0-3]$ & 0.10 \\
\hline AIS rachis & $0[0-2]$ & $0[0-3]$ & 0.02 \\
\hline \multicolumn{4}{|l|}{ Treatments } \\
\hline Mechanical ventilation & $130(74.2)$ & $33(45.8)$ & $<0.001$ \\
\hline Acetaminophen & $115(65.3)$ & $44(61.1)$ & 0.53 \\
\hline Benzodiazepine & $109(61.9)$ & $27(37.5)$ & $<0.001$ \\
\hline Opioids & $144(81.8)$ & $58(80.6)$ & 0.82 \\
\hline Neuro-muscular blockers & $34(19.3)$ & $3(4.2)$ & 0.002 \\
\hline Ketamine & $22(12.5)$ & $2(2.8)$ & 0.02 \\
\hline Craniectomy & $13(7.4)$ & $0(0.0)$ & - \\
\hline Transfusion & $0[0-2]$ & $0[0-6]$ & $<0.001$ \\
\hline In-hospital transport & $92(52.3)$ & $43(59.7)$ & 0.28 \\
\hline \multicolumn{4}{|l|}{ Outcome } \\
\hline 28-day mortality & $37(21.0)$ & $8(11.1)$ & 0.07 \\
\hline Days on mechanical ventilation & $7[4-14]$ & 4 [1-9] & $<0.001$ \\
\hline Days on vasopressor infusion & $2[1-4]$ & $2[1-4]$ & 0.40 \\
\hline Day in the ICU stay & $10[5-20]$ & $8[4-14]$ & 0.14 \\
\hline Days in the hospital & $13[7-24]$ & $10[6-15]$ & 0.10 \\
\hline \multicolumn{4}{|l|}{ Temperature rhythm } \\
\hline Period & $24[22-48]$ & $24[22-46]$ & 0.42 \\
\hline Mesor & $37.5[37.1-37.7]$ & $37.6[37.2-38.0]$ & 0.01 \\
\hline Amplitude & $0.35[0.27-0.55]$ & $0.34[0.26-0.54]$ & 0.63 \\
\hline
\end{tabular}

Results are expressed as median [IQR] for quantitative variables and number (\%) for categorical variables BMI Body mass index, SAPS2 Severity Assessment Physiology Score 2, ISS Injury Severity Score, AIS Abbreviated Injury Scale

entered into our statistical analysis although they may play a role in the temperature variations. However, as our results showed, one should note that neither acetaminophen nor transfusion affected the circadian temperature variation. Fifth, because of our system of file analysis, we did not note the occurrence of clinical outcomes such as sepsis or other complications. We considered that the 28-day mortality rate was a relevant and major outcome. Finally, it is a future challenge to transfer our exploratory findings to the bedside. However, in contrast to several studies [22, 48, 49], we show here that the circadian clock alterations occur early in 
Table 4 Survival analysis assessing 28-day mortality, patient characteristics, and circadian rhythm parameters of the temperature according to head trauma

\begin{tabular}{|c|c|c|c|c|c|c|c|c|}
\hline & \multicolumn{4}{|l|}{ Head trauma } & \multicolumn{4}{|l|}{ No head trauma } \\
\hline & \multicolumn{2}{|l|}{ Univariate } & \multicolumn{2}{|l|}{ Multivariate } & \multicolumn{2}{|l|}{ Univariate } & \multicolumn{2}{|l|}{ Multivariate } \\
\hline & $\mathrm{HR}[95 \% \mathrm{Cl}]$ & $p$ & $\mathrm{HR}[95 \% \mathrm{Cl}]$ & $p$ & $\mathrm{HR}[95 \% \mathrm{Cl}]$ & $p$ & $\mathrm{HR}[95 \% \mathrm{Cl}]$ & $p$ \\
\hline \multicolumn{9}{|l|}{ Clinical variables } \\
\hline Age & $1.04[1.02-1.06]$ & $<0.001$ & $1.04[1.02-1.06]$ & $<0.001$ & $1.07[1.03-1.12]$ & $<0.001$ & $1.10[1.04-1.17]$ & $<0.001$ \\
\hline Sex (male) & $1.68[0.74-3.82]$ & 0.22 & & & $2.36[0.29-19.17]$ & 0.42 & & \\
\hline Body mass index & $0.91[0.82-1.01]$ & 0.07 & & & $0.90[0.73-1.10]$ & 0.30 & & \\
\hline Glasgow Coma Scale & $0.96[0.87-1.05]$ & 0.33 & & & $0.84[0.75-0.95]$ & 0.004 & $0.77(0.65-0.91)$ & 0.003 \\
\hline Intracranial hypertension ${ }^{a}$ & $7.55[3.15-18.12]$ & $<0.001$ & & & - & - & - & - \\
\hline Surgery at admission & $0.90[0.47-1.72]$ & 0.75 & & & $0.71[0.14-3.52]$ & 0.68 & & \\
\hline ISS & $1.01[0.98-1.04]$ & 0.47 & & & $1.01[0.97-1.06]$ & 0.57 & & \\
\hline \multicolumn{9}{|l|}{ Temperature rhythm } \\
\hline Period & $1.00[0.97-1.02]$ & 0.74 & & & $1.05[0.99-1.11]$ & 0.11 & & \\
\hline Mesor & $0.41[0.25-0.65]$ & $<0.001$ & $0.40[0.23-0.70]$ & 0.001 & $0.73[0.23-2.29]$ & 0.59 & & \\
\hline Amplitude & $4.48[1.24-19.20]$ & 0.02 & $4.73[1.38-16.22]$ & 0.01 & $6.10[1.06-35.25]$ & 0.04 & $2.94[0.50-17.25]$ & 0.23 \\
\hline
\end{tabular}

The analyses were performed using Cox regression model to estimate hazard ratios (HR) and their 95\% confidence intervals (95\% Cls)

antracranial hypertension not included in the multivariate analysis owing to collinearity with head trauma
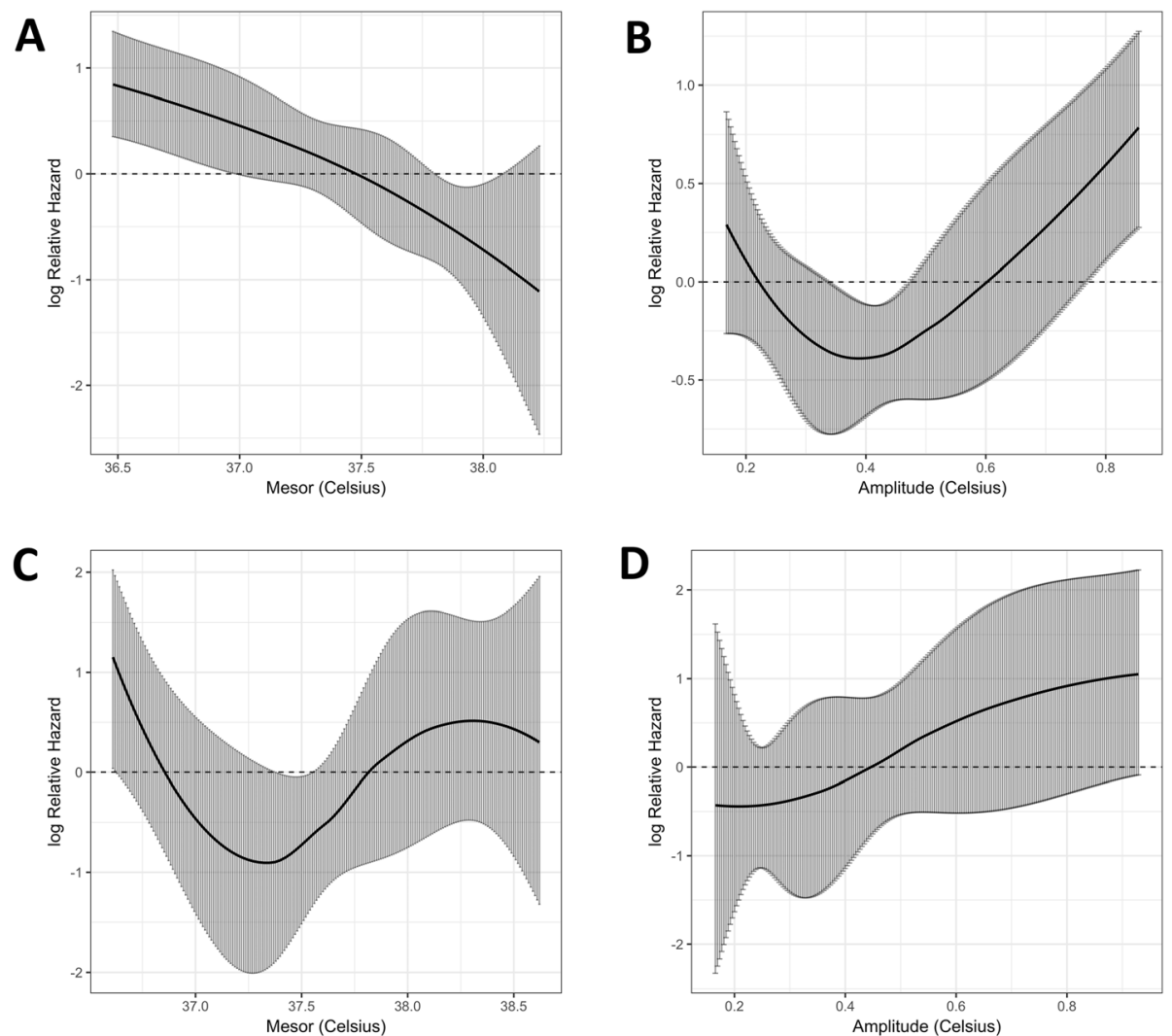

Fig. 5 Cox regression model fitting the association between temperature and the log relative hazard of 28-day mortality according to head trauma. a Mesor in head trauma group. b Amplitude in head trauma group. c Mesor in non-head trauma group. d Amplitude in non-head trauma group. Black curve represents the estimates of the model and gray bars represent the $95 \%$ confidence interval bands 
the hospitalization, suggesting that they probably reflect the severity of inflammation. The current evidence does not really support any specific interventions, although guidelines on sedation [50] already considered this concept.

\section{Conclusions}

Our findings underline the early disruption of the circadian clock of CBT after ICU admission for trauma. A level of CBT lower than the normal mesor value and high amplitude were identified as independent risk factors of 28-day mortality in the patients with head trauma. These results are not confirmed in the non-head trauma patients. Further studies will be required to determine the mechanisms and the pathological role of circadian clock disruption during the care of trauma patients.

\section{Supplementary information}

Supplementary information accompanies this paper at https://doi.org/10. 1186/s40560-019-0425-x.

Additional file 1. Example of a Fourier transformation followed by a Cosinor analysis to determine rhythmic parameters of the temperature. The Fourier transformation provides a power spectrum (grey lozenges) to determine the most probable rhythm period (red circle=highest power) from $48 \mathrm{~h}$ temperature data. Cosinor analysis is a periodic regression method that provides a sinusoidal approximation (dark line) of a rhythm from a set of temperature data (grey dots) with a given period determined with the Fourier transformation. In this example, analysis revealed a period of 22.5 hours, a mesor of $37.4^{\circ} \mathrm{C}$ and an amplitude of $0.72^{\circ} \mathrm{C}$.

Additional file 2. Definitions and interpretations of circadian parameters.

Additional file 3. Characteristic variables of a rhythmic function.

Additional file 4 Four examples of central core body temperature rhythm modelling. The dark lines represent the sinusoidal approximation of the Cosinor analysis from the set of temperature data (grey dots). Period, Mesor, and Amplitude of the temperature are respectively for trauma $\mathbf{A}: 6.4$ hours, $38.7^{\circ} \mathrm{C}, 0.35^{\circ} \mathrm{C}$; trauma $\mathbf{B}: 13.3$ hours, $37.8^{\circ} \mathrm{C}, 0.38^{\circ} \mathrm{C}$; trauma $\mathbf{C}: 24.0$ hours, $37.6^{\circ} \mathrm{C}, 0.30^{\circ} \mathrm{C}$; trauma $\mathbf{D}: 41.3$ hours, $37.6^{\circ} \mathrm{C}, 0.62^{\circ} \mathrm{C}$.

Additional file 5. Individual circadian parameter data after periodic regression.

Additional file 6. Factors influencing temperature rhythm parameters (i.e. Period, Mesor, and Amplitude): Univariate logistic regression analysis.

Additional file 7. Factors influencing temperature rhythm parameters (i.e. Mesor and Amplitude): Multivariate logistic regression analysis.

\section{Abbreviations}

BMI: Body mass index; CBT: Core body temperature; Cl: Confidence intervals; HR: Hazard ratio; ICU: Intensive care unit; IQR: Interquartile; ISS: Injury Severity Score; OR: Odds ratios; RASS: Richmond Agitation-Sedation Scale; SAPS2: Simplified Acute Physiology Score; SD: Standard deviation; SE: Standard error

\section{Acknowledgements}

The authors are indebted to the nursing staff of the polyvalent intensive care unit of North Hospital (Marseille, France) for providing the best care to their patients.

\section{Authors' contributions}

$\mathrm{ML}, \mathrm{AC}$, and $\mathrm{BC}$ conceived the project and conducted the study design. $\mathrm{AC}$, $B C, F A$, and $G D$ acquired the study data. $M L, A C, B C, E H, C V, J M$, and $L Z$ performed the analysis and interpretation of data. $\mathrm{KB}$ and $\mathrm{MB}$ performed the statistical analysis. All authors were involved in the drafting of the article and revised it critically for content, and all authors approved the final version for publication

\section{Funding}

This study received no funding.

\section{Availability of data and materials}

The datasets used and/or analyzed during the current study are available from the corresponding author on reasonable request.

\section{Ethics approval and consent to participate}

The research protocol has been approved by the Ethics Committee of the French Society of Anesthesia and Intensive Care Medicine (IRB CERAR00010254) and by the local Computer and Freedom Committee (CIL 201835).

Consent for publication

Not applicable

\section{Competing interests}

M. Leone discloses conflicts of interest with MSD, Pfizer, Aspen, Orion, Octapharma (lectures), and Amomed and Aguettant (consulting). The other authors declare that they have no competing interests.

\section{Author details}

${ }^{1}$ Service d'Anesthésie et de Réanimation, APHM, Hôpital Nord, Aix Marseille Université, Chemin des Bourrely, 13915 Marseille, France. ${ }^{2}$ Médecine Intensive - Réanimation, APHM, Hôpital Nord, Aix Marseille Université, Marseille, France. ${ }^{3} \mathrm{CNRS}$, IRD, MEPHI, IHU Méditerranée Infection, Aix Marseille Université, Marseille, France. ${ }^{4}$ APHM, EA 3279 CEReSS, School of Medicine La Timone Medical Campus, Health Service Research and Quality of Life Center, Aix Marseille Université, Marseille, France.

Received: 6 October 2019 Accepted: 29 December 2019

Published online: 06 January 2020

\section{References}

1. Bège T, Pauly V, Orleans V, Boyer L, Leone M. Epidemiology of trauma in France: mortality and risk factors based on a national medico-administrative database. Anaesth Crit Care Pain Med. 2019; https://doi.org/10.1016/j.accpm. 2019.02.007.

2. Dewar D, Moore FA, Moore EE, Balogh Z. Postinjury multiple organ failure. Injury. 2009:40(9):912-8.

3. Bhadra U, Thakkar N, Das P, Pal BM. Evolution of circadian rhythms: from bacteria to human. Sleep Med. 2017;35:49-61.

4. Takahashi JS, Hong H-K, Ko CH, McDearmon EL. The genetics of mammalian circadian order and disorder: implications for physiology and disease. Nat Rev Genet. 2008:9(10):764-75.

5. Mohawk JA, Green CB, Takahashi JS. Central and peripheral circadian clocks in mammals. Annu Rev Neurosci. 2012;35:445-62.

6. Hastings M, O'Neill JS, Maywood ES. Circadian clocks: regulators of endocrine and metabolic rhythms. J Endocrinol. 2007;195(2):187-98.

7. Eckel-Mahan K, Sassone-Corsi P. Metabolism and the circadian clock converge. Physiol Rev. 2013;93(1):107-35.

8. Esquifino Al, Cano P, Jiménez-Ortega V, Fernández-Mateos P, Cardinali DP. Neuroendocrine-immune correlates of circadian physiology: studies in experimental models of arthritis, ethanol feeding, aging, social isolation, and calorie restriction. Endocrine. 2007;32(1):1-19.

9. Thaiss CA, Levy M, Korem T, Dohnalová L, Shapiro H, Jaitin DA, et al. Microbiota diurnal rhythmicity programs host transcriptome oscillations. Cell. 2016;167(6):1495-510 e12.

10. Duffy JF, Dijk D-J. Getting through to circadian oscillators: why use constant routines? J Biol Rhythm. 2002;17(1):4-13.

11. Klerman EB, Gershengorn HB, Duffy JF, Kronauer RE. Comparisons of the variability of three markers of the human circadian pacemaker. J Biol Rhythm. 2002;17(2):181-93. 
12. Mackowiak PA. Concepts of fever. Arch Intern Med. 1998;158(17):1870-81.

13. Waterhouse J, Edwards B, Bedford P, Hughes A, Robinson K, Nevill A, et al. Thermoregulation during mild exercise at different circadian times. Chronobiol Int. 2004;21(2):253-75.

14. Billings ME, Watson NF. Circadian dysrhythmias in the intensive care unit. Crit Care Clin. 2015;31(3):393-402

15. Brainard J, Gobel M, Bartels K, Scott B, Koeppen M, Eckle T. Circadian rhythms in anesthesia and critical care medicine: potential importance of circadian disruptions. Semin Cardiothorac Vasc Anesth. 2015;19(1):49-60.

16. Mundigler G, Delle-Karth G, Koreny M, Zehetgruber M, Steindl-Munda P, Marktl W, et al. Impaired circadian rhythm of melatonin secretion in sedated critically ill patients with severe sepsis. Crit Care Med. 2002;30(3):536-40.

17. Gehlbach BK, Chapotot F, Leproult R, Whitmore H, Poston J, Pohlman M, et al. Temporal disorganization of circadian rhythmicity and sleep-wake regulation in mechanically ventilated patients receiving continuous intravenous sedation. Sleep. 2012;35(8):1105-14.

18. Chan M-C, Spieth PM, Quinn K, Parotto M, Zhang H, Slutsky AS. Circadian rhythms: from basic mechanisms to the intensive care unit. Crit Care Med. 2012;40(1):246-53.

19. Tweedie IE, Bell CF, Clegg A, Campbell IT, Minors DS, Waterhouse JM. Retrospective study of temperature rhythms of intensive care patients. Crit Care Med. 1989;17(11):1159-65.

20. Paul T, Lemmer B. Disturbance of circadian rhythms in analgosedated intensive care unit patients with and without craniocerebral injury. Chronobiol Int. 2007;24(1):45-61.

21. Gazendam JAC, Van Dongen HPA, Grant DA, Freedman NS, Zwaveling JH, Schwab RJ. Altered circadian rhythmicity in patients in the ICU. Chest. 2013; 144(2):483-9.

22. Coiffard B, Diallo AB, Culver A, Mezouar S, Hammad E, Vigne C, et al. Circadian rhythm disruption and sepsis in severe trauma patients. Shock. 2018. https://doi.org/10.1097/SHK.0000000000001241.

23. Toulouse E, Masseguin C, Lafont B, McGurk G, Harbonn A, A Roberts J, et al. French legal approach to clinical research. Anaesth Crit Care Pain Med. 2018;37(6):607-614.

24. Cotte J, Courjon F, Beaume S, Prunet B, Bordes J, N'Guyen C, et al. Vittel criteria for severe trauma triage: characteristics of over-triage. Anaesth Crit Care Pain Med. 2016;35:87-92.

25. Rossaint R, Bouillon B, Cerny V, Coats TJ, Duranteau J, Fernández-Mondéjar $E$, et al. The European guideline on management of major bleeding and coagulopathy following trauma: fourth edition. Crit Care. 2016;20:100.

26. Leone $M$, Constantin J-M, Dahyot-Fizelier $C$, Duracher-Gout $C$, JoannesBoyau $\mathrm{O}$, Langeron $\mathrm{O}$, et al. French intensive care unit organisation. Anaesth Crit Care Pain Med. 2018;37(6):625-7.

27. Refinetti R, Cornélissen G, Halberg F. Procedures for numerical analysis of circadian rhythms. Biol Rhythm Res. 2007;38(4):275-325.

28. Drewry AM, Fuller BM, Bailey TC, Hotchkiss RS. Body temperature patterns as a predictor of hospital-acquired sepsis in afebrile adult intensive care unit patients: a case-control study. Crit Care Lond Engl. 2013;17(5):R200.

29. Papaioannou VE, Chouvarda IG, Maglaveras NK, Pneumatikos IA. Temperature variability analysis using wavelets and multiscale entropy in patients with systemic inflammatory response syndrome, sepsis, and septic shock. Crit Care Lond Engl. 2012;16(2):R51.

30. Kleimeyer JP, Harris AHS, Sanford J, Maloney WJ, Kadry B, Bishop JA. Incidence and risk factors for postoperative hypothermia after orthopaedic surgery. J Am Acad Orthop Surg. 2018;26:e497-e503.

31. Kongsayreepong S, Chaibundit C, Chadpaibool J, Komoltri C, Suraseranivongse $S$, Suwannanonda $P$, et al. Predictor of core hypothermia and the surgical intensive care unit. Anesth Analg. 2003;96(3):826-33.

32. Sakr Y, Alhussami I, Nanchal R, Wunderink RG, Pellis T, Wittebole X, et al. Being overweight is associated with greater survival in ICU patients: results from the intensive care over nations audit. Crit Care Med. 2015;43(12):2623-32.

33. Shafi S, Elliott AC, Gentilello L. Is hypothermia simply a marker of shock and injury severity or an independent risk factor for mortality in trauma patients? Analysis of a large national trauma registry. J Trauma. 2005;59(5): 1081-5

34. Rincon F, Hunter K, Schorr C, Dellinger RP, Zanotti-Cavazzoni S. The epidemiology of spontaneous fever and hypothermia on admission of brain injury patients to intensive care units: a multicenter cohort study: clinical article. J Neurosurg. 2014;121(4):950-60.

35. Bourgouin S, Bège T, Masson C, Arnoux P-J, Mancini J, Garcia S, et al. Biomechanical characterisation of fresh and cadaverous human small intestine: applications for abdominal trauma. Med Biol Eng Comput. 2012; 50(12):1279-88

36. Vučković SM, Savić Vujović KR, Srebro DP, Medić BM, Vučetić ČS, Prostran MŠ, et al. Synergistic interaction between ketamine and magnesium in lowering body temperature in rats. Physiol Behav. 2014;127:45-53.

37. Papaioannou VE, Chouvarda IG, Maglaveras NK, Baltopoulos GI, Pneumatikos IA. Temperature multiscale entropy analysis: a promising marker for early prediction of mortality in septic patients. Physiol Meas. 2013;34(11):1449-66.

38. Peres Bota D, Lopes Ferreira F, Mélot C, Vincent JL. Body temperature alterations in the critically ill. Intensive Care Med. 2004;30(5):811-6.

39. Saxena M, Young P, Pilcher D, Bailey M, Harrison D, Bellomo R, et al. Early temperature and mortality in critically ill patients with acute neurological diseases: trauma and stroke differ from infection. Intensive Care Med. 2015; 41(5):823-32.

40. Kirkness CJ, Burr RL, Thompson HJ, Mitchell PH. Temperature rhythm in aneurysmal subarachnoid hemorrhage. Neurocrit Care. 2008;8(3):380-90.

41. Varela M, Calvo M, Chana M, Gomez-Mestre I, Asensio R, Galdos P. Clinical implications of temperature curve complexity in critically ill patients. Crit Care Med. 2005;33(12):2764-71.

42. Varela M, Churruca J, Gonzalez A, Martin A, Ode J, Galdos P. Temperature curve complexity predicts survival in critically ill patients. Am J Respir Crit Care Med. 2006;174(3):290-8.

43. Oldham MA, Lee HB, Desan PH. Circadian rhythm disruption in the critically ill: an opportunity for improving outcomes. Crit Care Med. 2016;44(1):20717.

44. McKenna HT, Reiss IK, Martin DS. The significance of circadian rhythms and dysrhythmias in critical illness. J Intensive Care Soc. 2017;18(2):121-9.

45. Lefrant J-Y, Muller L, de La Coussaye JE, Benbabaali M, Lebris C, Zeitoun N, et al. Temperature measurement in intensive care patients: comparison of urinary bladder, oesophageal, rectal, axillary, and inguinal methods versus pulmonary artery core method. Intensive Care Med. 2003;29(3):414-8.

46. Weinert $D$, Waterhouse J. The circadian rhythm of core temperature: effects of physical activity and aging. Physiol Behav. 2007;90(2-3):246-56.

47. Mendoza J. Circadian clocks: setting time by food. J Neuroendocrinol. 2007; 19(2):127-37.

48. Madrid-Navarro C, Sanchez-Galvez R, Martinez-Nicolas A, Marina R, Garcia J, Madrid J, et al. Disruption of circadian rhythms and delirium, sleep impairment and sepsis in critically ill patients. Potential therapeutic implications for increased light-dark contrast and melatonin therapy in an ICU environment. Curr Pharm Des. 2015;21:3453-68.

49. Sertaridou E, Chouvarda I, Arvanitidis K, Filidou E, Kolios G, Pnevmatikos I, et al. Melatonin and cortisol exhibit different circadian rhythm profiles during septic shock depending on timing of onset: a prospective observational study. Ann Intensive Care. 2018;8:118.

50. Devlin J, Skrobik Y, Gélinas C, Needham D, Slooter A, Pandharipande P, et al. Clinical practice guidelines for the prevention and management of pain agitation/sedation, delirium, immobility, and sleep disruption in adult patients in the ICU. Crit Care Med. 2018;46:e825-73.

\section{Publisher's Note}

Springer Nature remains neutral with regard to jurisdictional claims in published maps and institutional affiliations.

Ready to submit your research? Choose BMC and benefit from:

- fast, convenient online submission

- thorough peer review by experienced researchers in your field

- rapid publication on acceptance

- support for research data, including large and complex data types

- gold Open Access which fosters wider collaboration and increased citations

- maximum visibility for your research: over $100 \mathrm{M}$ website views per year

At $\mathrm{BMC}$, research is always in progress.

Learn more biomedcentral.com/submission 